Вестник ВГУ. Серия: Право

УДК 347.73

DOI https://doi.org/10.17308/vsu.proc.law.2020.3/2988

\title{
ОПЕРАТОРЫ ЭЛЕКТРОННЫХ ПЛОЩАДОК КАК СУБЪЕКТЫ НАЛОГОВОГО ПРАВА*
}

\author{
О. И. Лютова \\ Национальный исследовательский университет \\ "Высшая школа эконолики" \\ Поступила в редакцию 25 декабря 2019 г.
}

\begin{abstract}
Аннотация: проведено исследование особенностей правового регулирования отношений, связанных с исчислениел и уплатой налога на профбессиональный доход, в частности с точки зрения определения правового статуса нового участника налоговых отношений - оператора электронной площадки. Указываются пути совершенствования правового регулирования статуса операторов электронных плошадок за счет использования илеюшихся в налоговол законодательстве Российской Федерации классических моделей налоговых отношений с участиел налогового агента. Ключевые слова: оператор электронной площадки, налогоплательщик, салозанятый, инфорлационные технологии, налоговый агент, специальный налоговый режил, налог на предпринимательский доход, модель налогообложения, Налоговый кодекс Российской Федераиии.
\end{abstract}

\begin{abstract}
: a study was made of the features of the legal regulation of relations related to the calculation and payment of tax on professional income, in particular, from the point of view of determining the legal status of a new participant in tax relations - the operator of the electronic platform. The ways of improving the legal regulation of the status of electronic platform operators are indicated through the use of classical models of tax relations involving a tax agent that are available in the tax legislation of the Russian Federation. Key words: electronic platform operator, taxpayer, self-employed, information Technology, tax agent, special tax treatment, business income tax, tax model, Tax Code of the Russian Federation.
\end{abstract}

$m$

Процессы распространения использования технических устройств и обеспечивающих их информационных технологий оказывают неуклонное влияние на все сфреры общественной жизни. Налоговые отношения, в свою очередь, стали сферой активного приложения таких технологий, в результате чего появляются новые правовые нормы и институты, а также модернизируются уже существующие. По справедливому замечанию В. Е. Родыгиной, «налоговая система... не должна быть препятствием на пути в сторону цифровизации: применение цифровых технологий в сфере налогового администрирования является важнейшим этапом достижения поставленной цели» ${ }^{1}$.

* Исследование выполнено при финансовой поддержке РФФИ в рамках научного проекта № 18-29-16107 мк «Исследование и обоснование выбора модели налогообложения в эпоху цифровой трансформации».

1 Финансовое право в условиях развития цифровой экономики / под ред. И. А. Цинделиани. М., 2019. С. 243.

(С) Лютова О. И., 2020 


\section{Финансовое право. Налоговое право}

В связи с этим ФНС России, изучая лучший опыт из мировой практики применения в налоговом администрировании информационных технологий ${ }^{2}$, активно использует в своей деятельности искусственный интеллект, «умные» порталы, технологии больших данных, а также мобильные устройства. Примером активного применения последних является мобильное приложение «Мой налог», которое используется, в том числе при уплате налога на профессиональный доход, исчисляемый и уплачиваемый в ходе проведения эксперимента по установлению соответствующего специального налогового режима ${ }^{3}$. Такой эксперимент проводится в отношении лиц, осуществляющих деятельность на территории г. Москвы, Московской и Калужской областей, а также в Республике Татарстан. Продлится такой эксперимент до 1 января 2028 г. При этом есть основания полагать, что временные рамки и статус эксперимента в отношении исследуемого специального налогового режима используются налоговым законодателем для повышения прозрачности осуществления предпринимательской деятельности ${ }^{4}$, а также стимулирования к "выходу из тени» и юридической легализации лиц, самостоятельно получающих доходы, независимо от наличия или отсутствия у них статуса индивидуального предпринимателя. Этот фракт подтверждается также в различных выступлениях представителей налоговых органов. Например, К. В. Новоселов подчеркивает, что «основная задача, которая стояла при введении закона, - легализация граждан, осуществляющих предпринимательскую деятельность без регистрации, в правовом поле» ${ }^{5}$. Многие исследователи при этом также указывают, что в основе мотивировки разработки и принятия нормативного акта для самозанятых лиц лежит вполне конкретная цель пополнение бюджета за счет поиска нового источника финансирования 6 . Все это позволяет констатировать очевидность в ближайшей перспективе имплементации норм о налоге на профессиональный доход в Налоговый

${ }^{2}$ В рамках Форума по налоговому администрированию ОЭСР ФНС России курирует работу Сообщества по цифровой трансформации, задача которого - изучить опыт лучшей практики использования цифровых технологий в налоговом администрировании. URL: http://nalogoved.ru/news/8098.html (дата обращения: 26.09.2019).

${ }^{3} \mathrm{O}$ проведении эксперимента по установлению специального налогового режима «Налог на профессиональный доход» в городе фредерального значения Москве, в Московской и Калужской областях, а также в Республике Татарстан (Татарстан) : фредер. закон от 27 ноября 2018 г. № 422-ФЗ // Собр. законодательства Рос. Федерации. 2018. № 49 (ч. 1). Ст. 7494.

${ }^{4}$ См.: Михайлов А. В. Перспективы развития законодательства о предпринимательской деятельности в условиях цифровой экономики // Предпринимательское право. Приложение «Право и бизнес». 2019. № 3. С. 7-13.

5 Закон о самозанятых принят с целью их легализации, и не надо использовать его для минимизации налоговых платежей! Интервью с К. В. Новоселовым // Трудовое право. 2019. № 7. С. 5.

${ }^{6}$ См., например: Алексеевская $A$. Социальные аспекты самозанятости. Кто может решиться использовать такую форму и легализоваться? // Трудовое право. 2019. № 7. C. 23-32. 


\section{Вестник ВГУ. Серия: Право}

кодекс Российской Федерации (далее - НК РФ) с дальнейшим унифицированием соответствующих норм с иными положениями НК РФ. Таким образом, все участники правоотношений, связанных с налогом на профессиональный доход, должны идентифицироваться в качестве тех или иных субъектов налоговых отношений, статус которых урегулирован НК РФ.

Необходимо отметить что механизмы налогово-правового регулирования специального налогового режима «Налог на профессиональный доход» уже являлись предметом критического анализа исследователей-налоговедов ${ }^{7}$. Однако содержание подобных работ касалось исключительно вопросов регулирования налоговым законодательством прав и обязанностей налогоплательщика налога на профессиональный доход - так называемого «самозанятого» лица ${ }^{8}$. При этом для всестороннего обеспечения интересов как государства, так и налогоплательщиков налога на профессиональный доход необходимо четкое и однозначное правовое регулирование правового статуса всех участников правоотношений, связанных с исчислением и уплатой налога на профессиональный доход, осуществляемое на основании Федерального закона от 27 ноября 2018 г. № 422-Ф3 «О проведении эксперимента по установлению специального налогового режима «Налог на профессиональный доход» в городе федерального значения Москве, в Московской и Калужской областях, а также в Республике Татарстан (Татарстан)» (далее - ФЗ № 422).

Прежде всего, это касается такого субъекта, как оператор электронной площадки. В настоящее время в этом качестве может выступить организация или индивидуальный предприниматель, оказывающие с использованием сети «Интернет» услуги по предоставлению технических, организационных, информационных и иных возможностей с применением информационных технологий и систем для установления контактов и заключения сделок по реализации товаров (работ, услуг, имущественных м прав) между продавцами (исполнителями) и покупателями (заказчика-

을 ми) $)^{9}$. При этом НК РФ не содержит упоминания о таком участнике налоговых отношений, как оператор электронной площадки, ни в ст. 9 НК РФ «Участники отношений, регулируемых законодательством о налогах

${ }^{7}$ См., например: Копина А. А. Налоговые эксперименты // Налоги. 2018. № 19. C. $1,3-4 ; E$ же. Новый специальный налоговый режим для фризических лиц налог на профессиональный доход // Там же. № 20. С. 1, 3-8 ; Ручкина Г. Ф. Новые специальные налоговые режимы в законодательстве Российской Федерации как реализация публичных интересов государства // Там же. 2019. № 1. С. 28-33 ; Тропская C. С. Налогообложение самозанятых и цифровая экономика : налог на профессиональный доход // Финансовое право. 2019. № 5. С. 22-26; и др.

${ }^{8}$ Cм., например: Шуваев E. A. Статус гражданина, зарегистрированного в качестве самозанятого, и проблемы налогообложения доходов самозанятых лиц // Электронное приложение к Рос. юрид. журналу. 2019. № 2. С. 66-72.

9 О проведении эксперимента по установлению специального налогового режима «Налог на профессиональный доход» в городе федерального значения Москве, в Московской и Калужской областях, а также в Республике Татарстан (Татарстан) : федер. закон от 27 ноября 2018 г. № 422-ФЗ (ч. 5 ст. 3) // Собр. законодательства Рос. Федерации. 2018. № 49 (ч. 1). Ст. 7494. 


\section{Финансовое право. Налоговое право}

и сборах», ни в иных статьях части первой или второй НК РФ. Таким образом, налогово-правовой статус оператора электронной площадки в настоящее время ограничивается посредническими функциями, которые заключаются в обеспечении передачи налоговым органам информации о совершенных налогоплательщиком-самозанятым операций, являющихся объектами налогообложения налогом на предпринимательский доход, а также в перечислении соответствующего налога в бюджет по поручению плательщика.

Что касается налога на профессиональный доход, то он подлежит исчислению налоговым органом на основании полученных от операторов электронных площадок сведений, в результате чего налогоплательщику направляется уведомление, получив которое он может уполномочить оператора электронной площадки или кредитную организацию на уплату суммы налога на профессиональный доход, указанной в налоговом уведомлении. Тем самым для участников налоговых отношений по исчислению и уплате налога на профессиональный доход устанавливается исключительно электронный вариант взаимодействия, что пока не свойственно для отношений лиц, осуществляющих уплату налогов на общем режиме налогообложения, а также использующих иные специальные налоговые режимы.

Такой механизм правового регулирования транзакционного налогообложения, осуществляемого при реализации норм налогового законодательства о налоге на профессиональный доход, позволяет обобщить и сформулировать следующие принципиальные вопросы, необходимые, на наш взгляд, к разрешению для осуществления возможности дальнейшего развития налогообложения самозанятых, а также их активного привлечения к получению соответствующего статуса.

Во-первых, фактически отсутствует правовое регулирование процедур взаимодействия участников правоотношений, возникающих при исчислении и уплате налога на профессиональный доход, а также требования, предъявляемые к операторам электронных площадок. Так, в п. 2 ст. 3 ФЗ № 422 указано, что «порядок использования мобильного приложения «Мой налог» размещается в сети «Интернет» на официальном сайте федерального органа исполнительной власти, уполномоченного по контролю и надзору в области налогов и сборов». Во исполнение этих требований на сайте nalog.ru в PDF-формате представлен документ, не имеющий названия и характерных для официального акта реквизитов в виде даты, номера и т. п., имеющий название «Протокол информационного обмена, порядок информационного взаимодействия, требования (критерии) к операторам электронных площадок и кредитным организациям, осуществляющим взаимодействие с налоговыми органами». По терминологии, используемой, например, А. В. Деминым и А. В. Николаевым, это квазинормативный источник ${ }^{10}$, де-юре не имеющий силы, но де-факто облада-

${ }^{10}$ См.: Делин А. В., Николаев А. В. Фактическое право на доход в налоговом праве : комментарий законодательства и судебной практики. Доступ из справ.-правовой системы «КонсультантПлюс». 


\section{Вестник ВГУ. Серия: Право}

ющий значительным авторитетом, определенным статусом ФНС России. С формально-юридической точки зрения ФНС России имеет право принимать ненормативные (индивидуальные) и нормативные акты, причем только в пределах своей компетенции, обозначенной в постановлении Правительства РФ от 30 сентября 2004 г. № 506 «Об утверждении Положения о Федеральной налоговой службе». Последние обычно имеют форму писем или приказов. Это означает, что вышеуказанные требования не имеют обязательной юридической силы и фактически могут рассматриваться теми субъектами, кому они адресованы (операторами электронных площадок и кредитными организациями), в качестве официального разъяснения рекомендательного характера.

В этой ситуации видится только один выход: на наш взгляд, однозначна необходимость принятия нормативного правового акта, устанавливающего соответствующие требования к операторам электронных площадок и кредитным организациям. Стоит отметить, что такая необходимость обусловлена целями защиты прав и обеспечения интересов налогоплательщиков, которые пользуются услугами операторов электронных площадок. Для этого считаем необходимым установить адекватные реальностям сложившегося рынка «пороговые» требования к операторам электронных площадок, необходимые и достаточные для качественного обслуживания налогоплательщиков, которые будут предусматривать, например, механизм взаимодействия налогоплательщика и оператора электронной площадки с целью уточнения информации до ее передачи в ФНС России. Это положение связано с возможными техническими ошибками в работе операторов. При этом его включение в соответствующий нормативный документ фактически поможет снять нагрузку с налоговых органов, вызванную участием в процедуре обжалования результатов налогового контроля исчисления и уплаты сумм налога на профессиональный доход, которая

m гипотетически возможна в случаях совершения таких ошибок. На наш

이 взгляд, такое правовое регулирование должен создать Минпромторг Росс сии, который является федеральным органом исполнительной власти, ิ осуществляющим функции по выработке государственной политики и

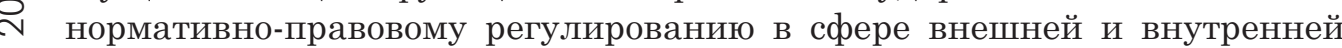
торговли, в том числе при продаже товаров с использованием информа-

228 ционно-телекоммуникационной сети «Интернет» ${ }^{11}$.

Во-вторых, правоприменительные трудности в ближайшей перспективе вызовет неопределенность правового статуса операторов электронных площадок с точки зрения налогово-правового регулирования.

На основании сформулированных выше положений о роли операторов электронных площадок считаем их правовой статус неопределенным с точки зрения налогового законодательства, что обусловлено наличием у операторов неких посреднических функций, предусмотренных без однозначного определения их как одного из участников налоговых право-

${ }^{11}$ О Министерстве промышленности и торговли Российской Федерации : постановление Правительства РФ от 5 июня 2008 г. № 438 // Собр. законодательства Рос. Федерации. 2008. № 24. Ст. 2868. 


\section{Финансовое право. Налоговое право}

отношений, виды которых указаны в ст. 9 НК РФ. Для идентификации операторов цифровых площадок в качестве субъекта налогового права необходимо, прежде всего, выбрать наиболее адекватную для специального налогового режима в виде налога на профессиональный доход модель его исчисления и уплаты.

Как известно, на современном этапе развития налоговых отношений для Российской Федерации характерны три модели отношений налогоплательщиков и налоговых органов, связанных с исчислением налогов:

1) налог рассчитывает налоговый орган и направляет уведомление налогоплательщику;

2) налог исчисляет сам налогоплательщик без чьего-либо посредничества;

3) обязанность расчета, удержания и перечисления налога возложена на налогового агента.

При этом для налогоплательщиков-физических лиц, не имеющих статуса индивидуального предпринимателя (к которым также относится и часть самозанятых), поимущественные налоги исчисляют налоговые органы на основании сведений, получаемых ими от иных субъектов (обычно также властных, что гарантирует их достоверность, например от органов МВД России в отношении транспортного налога), а подоходные - налоговые агенты (налог на доходы физических лиц). В связи с этим исчисление подоходного по своей юридической природе налога на профессиональный доход для самозанятых налоговыми органами, несмотря на относительное удобство этой ситуации для налогоплательщиков, не является логичной с точки зрения конструирования системы правового регулирования налоговых отношений по исчислению налогов. На наш взгляд, можно сконструировать следующий вариант трансформации: признать операторов электронных площадок налоговыми агентами для целей исчисления налога на предпринимательский доход и трансформировать соответствующий механизм трехсторонних отношений: государство в лице налогового органа, налогоплательщик и налоговый агент - оператор электронной площадки.

Так, одним из частных субъектов налоговых отношений выступает налоговый агент, который в соответствии со ст. 24 НК РФ несет обязанности по исчислению, удержанию у налогоплательщика и перечислению налогов в бюджетную систему Российской Федерации. При этом в традиционном понимании российского налогового законодательства обязанности налоговых агентов могут быть возложены на организации, индивидуальных предпринимателей, а также нотариусов и адвокатов, осуществляющих выплаты физическим лицам каких-либо доходов либо при совершении иных указанных в НК РФ операций (например, покупка и аренда государственного имущества). Таким образом, налоговым агентом является лицо, которому достоверно известно о доходах налогоплательщика в силу того, что это лицо само является их источником.

Как известно, в ситуации с самозанятыми правоотношения типа «работник-работодатель» изначально парадоксальны, поскольку смысл статуса самозанятого как раз и заключается в отсутствии работодателя и 


\section{Вестник ВГУ. Серия: Право}

самостоятельном поиске физическим лицом или индивидуальным предпринимателем возможностей для заработка. При этом количество самозанятых, по официальным сведениям, на конец 2018 г. составило более 2 млн человек ${ }^{12}$, а в динамике постоянно увеличивается. Чаще всего к этой категории лиц относятся таксисты, репетиторы, разнорабочие и помощники по дому и т. п. Логично предположить, что со временем их число будет увеличиваться, что вызовет дополнительную нагрузку на налоговые органы, связанную с расчетами налога на профессиональный доход, а также с необходимостью разрешения споров относительно сумм этого налога.

Дополнительным аргументом в пользу рассматриваемой идеи возможности окончательного превращения посреднического статуса операторов электронных платформ в налогово-агентский статус видятся в близости отдельных механизмов правового регулирования отношений налогоплательщиков с операторами и налогоплательщиков с налоговыми агентами. Например, по смыслу подп. 5 п. 3 ст. 45 НК РФ при неудержании налога налоговым агентом обязанность по его уплате несет налогоплательщик, что коррелирует с положениями ст. 14 ФЗ № 422 , в соответствии с которыми в случае неисполнения обязанности по перечислению налога на предпринимательский доход оператором электронной площадки обязанность по его уплате возлагается на налогоплательщика.

Таким образом, полагаем уместным в краткосрочной перспективе в вопросах правового статуса операторов электронных площадок рассматривать налоговое право как прагматическую модель (т. е. модель, под которую, по терминологии Д. М. Жилина ${ }^{13}$, «подгоняется» реальность) и не создавать новых вариантов правового регулирования без объективной на то надобности при наличии адекватных сложившейся ситуации юридических конструкций. Безусловно, налоговые отношения будут продолжать m трансформироваться под влиянием технического процесса и в результате 을 масштабной реализации мероприятий цифровизации. Эти события, без с сомнения, приведут в будущем к выработке новых механизмов правового 尺े регулирования в налоговом законодательстве России, в результате чего участие в налоговых отношениях операторов электронных площадок, очевидно, будет более масштабным. Однако в настоящее время можно

230 констатировать, прежде всего, технологическую неготовность к таким изменениям, а также отсутствие научной и законодательной концепций трансформации налогового права в цифровую эпоху. Это дает основания полагать, что в современных условиях в качестве временной меры логично использовать имеющиеся в НК РФ правовые конструкции для обеспечения единства целей и задач налогово-правового регулирования.

Действительно, модель налоговых отношений с привлечением налоговых агентов далеко не нова для российского налогового права и имеет определенные выгоды для всех участников налоговых отношений. Об-

12 URL: https://www.business-gazeta.ru/news/406407\#19 (дата обращения: 16.12.2019).

${ }^{13}$ См.: Жилин Д. М. Теория систем : опыт построения курса. М., 2007. С. 30-32. 


\section{Финансовое право. Налоговое право}

щеизвестно, что использование модели отношений с привлечением налоговых агентов имеет для государства ряд неоспоримых преимуществ, связанных с отсутствием необходимости «точечного» администрирования налогов и сборов в отношении значительного числа налогоплательщиков, чаще всего не обладающих соответствующими знаниями и компетенщией для осуществления возможности самостоятельного расчета налогов. Аналогичные преимущества видятся в признании операторов электронных площадок налоговыми агентами: государство освобождается от обязанностей бюджетных расходов на администрирование исчисления налога на предпринимательский доход и необходимости непосредственного взаимодействия с каждым из самозанятых, а физические лица-налогоплательщики «делегируют» свою обязанность по исчислению, удержанию и перечислению налога на предпринимательский доход иному лицу.

Безусловным риском в такой ситуации является возрастающая нагрузка на операторов электронных площадок, которые, предположительно, обладают исключительно техническим потенциалом, но не интеллектуальным ресурсом, позволяющим квалифицированно осуществлять мониторинг налогового законодательства и проводить соответствующие расчеты и иные необходимые операции.

При этом важно отметить, что существующая модель правового регулирования, предполагающая исчисление налога на предпринимательский доход налоговым органом, не является однозначно выгодной для налогоплательщика. В свою очередь, возложение этой обязанности на частного субъекта (оператора электронной площадки или самозанятого-налогоплательщика) не влечет для них только лишь негативные последствия без должной балансировки их возможностями. Поэтому в качестве вывода считаем возможным указать положительные и негативные стороны трансформации правового статуса оператора электронной площадки в налогового агента.

Положительные стороны использования модели правового регулирования, в соответствии с которой осуществляется наделение операторов электронных площадок статусом налогового агента:

1) отсутствие необходимости расходования бюджетных средств в связи с осуществлением расчетов сумм налога на профессиональный доход государственными (налоговыми) органами. Справедливо замечание А. Г. Иванова, который достаточно точно отмечает особенность статуса налогового агента: «...переложение обязанностей публичных органов на иных субъектов - для государства неплохая идея: субъект выполняет работу публичных органов бесплатно» ${ }^{14}$;

2) повышение общего уровня налоговой культуры населения за счет необходимости выбора того или иного налогового агента - оператора электронной площадки, а также налогового консультанта;

3) обеспечение стабильности налогового законодательства Российской Федерации в связи с отсутствием необходимости создания новых юриди-

${ }^{14}$ Иванов А. Г. Пути совершенствования налогового администрирования // Налоговое администрирование : ежегодник. М., 2008. С. 176. 


\section{Вестник ВГУ. Серия: Право}

ческих конструкций налоговых отношений. Как отмечал Ж.-Л. Бержель, «нынешнее право создавалось на основе права вчерашнего дня» ${ }^{15}$. Действительно, использование существующих моделей отношений в сфере налогообложения позволяет реализовать принцип нормативной экономии и обеспечить относительную стабильность основ правового регулирования налогового законодательства;

4) возможность для налогоплательщика контролировать осуществление расчета налога на предпринимательский доход, а в случае его несогласия с суммой налога осуществлять его корректировку в отношениях с частными субъектами, а не с налоговыми органами, что предполагает снижение нагрузки налоговых органов.

Отрицательные черты трансформации налогово-правового статуса операторов электронных площадок в налоговых агентов видятся автору в следующем:

1) перераспределение расходов, связанных с переводом обязанностей по исчислению налогов от налоговых органов к частным субъектам - налогоплательщикам или операторам электронных площадок с обязательным привлечением в обоих вариантах специалистов в сфере налогообложения;

2) возможная монополизация рынка услуг, предоставляемых операторами электронных площадок, связанная с усложнением требований к ним, что приведет к монополизации соответствующих цен.

Таким образом, по мнению автора, несмотря на указанные риски и недостатки, всем сторонам налоговых отношений, связанных с подоходным налогообложением самозанятых, было бы удобно использовать модель отношений с участием посредника в статусе налогового агента. В связи с этим считаем в настоящее время актуальным вопрос о необходимости расширения понятия налоговых агентов в связи с появлением нового специального налогового режима в виде налога на предпринимательский доход и новых участников налоговых отношений - самозанятых и операторов электронных площадок.

${ }^{15}$ Бержель Ж.-Л. Общая теория права : пер. с фр. М., 2000. С. 196.

Национальный исследовательский институт "Высшая школа эконолики"

Лютова О. И., кандидат юридических наук, научный сотрудник отдела адлинистративного моделирования деятельности органов исполнительной власти Института государственного и мунииипального управления

E-mail: olytova@hse.ru
National Research Institute "Higher School of Economics"

Lyutova O. I., Candidate of Legal Sciences, Researcher at the Administrative Modeling of the Activities of Executive Authorities of the Institute of State and Municipal Administration Department

E-mail: olytova@hse.ru 